\title{
IL-12 upregulates TIM-3 expression and induces $T$ cell exhaustion in patients with follicular B cell non-Hodgkin lymphoma
}

\author{
Zhi-Zhang Yang, ${ }^{1}$ Deanna M. Grote, ${ }^{1}$ Steven C. Ziesmer, ${ }^{1}$ Toshiro Niki, ${ }^{2}$ Mitsuomi Hirashima, ${ }^{3}$ \\ Anne J. Novak, ${ }^{1}$ Thomas E. Witzig, ${ }^{1}$ and Stephen M. Ansell1

\begin{abstract}
1Division of Hematology and Internal Medicine, Mayo Clinic, Rochester, Minnesota, USA. ${ }^{2}$ GalPharma Co., Takamatsu, Kagawa, Japan.
\end{abstract} \\ 3Department of Immunology and Immunopathology, Faculty of Medicine, Kagawa University, Kita-gun, Kagawa, Japan.
}

\begin{abstract}
The cytokine IL-12 induces IFN- $\gamma$ production by T and NK cells. In preclinical models, it contributes to antitumor immunity. However, in clinical testing, it has shown limited benefit in patients with any one of a variety of malignancies. Moreover, in a clinical trial testing a combination of IL-12 and rituximab in patients with follicular B cell non-Hodgkin lymphoma (FL), those treated with IL-12 showed a lower response rate, suggesting that IL-12 actually plays a detrimental role. Here, we investigated whether the failure of IL-12 treatment for FL was due to $T$ cell exhaustion, a condition characterized by reduced $T$ cell differentiation, proliferation, and function, which has been observed in chronic viral infection. We found that extended exposure to IL-12 induced $\mathrm{T}$ cell exhaustion and contributed to the poor prognosis in FL patients. Long-term exposure of freshly isolated human $\mathrm{CD}^{+} \mathrm{T}$ cells to IL-12 in vitro caused $\mathrm{T}$ cell dysfunction and induced expression of TIM-3, a T cell immunoglobulin and mucin domain protein with a known role in $\mathrm{T}$ cell exhaustion, via an IFN- $\gamma$-independent mechanism. TIM-3 was required for the negative effect of IL-12 on T cell function. Importantly, TIM-3 also was highly expressed on intratumoral $\mathrm{T}$ cells that displayed marked functional impairment. Our findings identify IL-12- and TIM-3-mediated exhaustion of T cells as a mechanism for poor clinical outcome when IL-12 is administered to FL patients.
\end{abstract}

\section{Introduction}

Follicular B cell non-Hodgkin lymphoma (FL), the second most frequent type of non-Hodgkin's lymphoma (NHL), is characterized by the presence of a significant number of $\mathrm{T}$ cells in the tumor microenvironment that have a substantial impact on antitumor immunity and patient outcome $(1,2)$. Previous studies have shown that the type of $\mathrm{T}$ cell-mediated immune response, which is regulated by the cytokine milieu, determines antitumor immunity (3-5), thereby having an impact on patient outcome in FL (6-8). Recently, a type of immune response termed $T$ cell exhaustion, describing the condition in which $T$ cells exhibit reduced differentiation, proliferation, and effector function, has been characterized and validated in chronic viral infections, such as lymphocytic choriomeningitis $(9,10), \operatorname{AIDS}(11,12)$, and hepatitis (13-15). In tumors, it has been observed that intratumoral $\mathrm{T}$ cells display a phenotypic and functional profile similar to that of exhausted T cells from chronic viral infection $(16,17)$, suggesting that intratumoral $\mathrm{T}$ cells can be functionally exhausted due to tumor antigen overload (18).

IL-12 is a heterodimeric cytokine composed of p35 and p40 subunits; it induces IFN- $\gamma$ production by $\mathrm{T}$ and NK cells and contributes to antitumor immunity. However, administration of IL-12 to boost antitumor immunity in cancer patients has been shown to have minimal or no clinical benefit (19). In fact, a clinical trial of IL-12 in combination with rituximab in FL showed a lower response rate in patients treated with the combination than in patients treated with rituximab alone (20), suggesting that, in contrast with the observations in vitro or in vivo in mice,

Conflict of interest: The authors have declared that no conflict of interest exists. Citation for this article: J Clin Invest. 2012;122(4):1271-1282. doi:10.1172/JCI59806.
IL-12 actually plays a detrimental role in lymphoma patients. However, the underlying mechanism mediating inferior effects of IL-12 on FL patients is unknown.

TIM-3, a family member of $\mathrm{T}$ cell immunoglobulin and mucin domain proteins, has been shown to inhibit $\mathrm{T}_{\mathrm{H}} 1$-mediated autoand alloimmune responses and to promote immunological tolerance $(21,22)$. Recently, a growing number of studies have suggested that, instead of functioning as an inhibitor for $\mathrm{T}_{\mathrm{H}} 1$ cells, TIM-3 actually plays a crucial role in mediating $T$ cell exhaustion and contributing to negative immune responses both in viral infections and in tumors (23-28). However, its biological and clinical relevance in cancer patients and what pathway is involved in the regulation of TIM-3 expression on T cells is completely unknown.

In FL, previous studies have shown that intratumoral T cells display decreased proliferative capacity and effector function (29-31), suggesting the existence of $\mathrm{T}$ cell dysfunction or exhaustion in the tumor microenvironment of FL. Given the crucial role of TIM-3 in $\mathrm{T}$ cell dysfunction or exhaustion and inferior effects of IL-12 on FL patients, we determined in the present study whether T cell exhaustion exists in FL and is possibly associated with TIM-3 expression, whether IL-12 contributes to T cell exhaustion, and whether T cell exhaustion has an effect on patient outcome in FL patients.

\section{Results}

Serum levels of IL-12 are elevated and correlate with poor outcome in FL. To identify cytokines that may be important in FL, we performed a multiplex ELISA (Luminex) on serum specimens obtained from previously untreated patients who were enrolled in a clinical trial testing the efficacy of the anti-CD20 mAb rituximab as initial therapy and compared the levels of 30 cytokines in these patients to those in healthy controls. Similar to a previous work (32), we 
observed that serum IL-12 levels were elevated in untreated FL patients when compared with healthy individuals (Figure 1A). We then correlated patient clinical data with serum IL-12 levels and found that higher pretreatment serum IL-12 levels were associated with a shorter progression-free survival (Figure 1B).

We next determined which cells were producing IL-12 by both ELISA and intracellular cytokine staining. Freshly isolated T cells, $\mathrm{B}$ cells, or monocytes from peripheral blood of healthy individuals or biopsy specimens of FL patients were cultured in the absence or presence of IFN- $\gamma$ followed by treatment with LPS. The culture supernatants were collected, and IL-12 levels were measured by ELISA. Cells were then restimulated with phorbol myristate acetate/ionomycin (PMA/ion) in the presence of brefeldin A for 5 hours and subjected to cytokine intracellular staining. As shown in Figure 1C, monocytes stimulated with IFN- $\gamma$ plus LPS secreted the highest levels of IL-12, while B cells from FL also produced a substantial amount of IL-12. In contrast, B cells from healthy individuals and $\mathrm{T}$ cells from either healthy individuals or FL patients were not able to produce IL-12 in response to IFN- $\gamma /$ LPS stimulation. Corresponding to these data, we found by flow cytometry that the cells stimulated with IFN- $\gamma /$ LPS that were able to produce IL-12 were monocytes from both healthy individuals and FL patients as well as B cells only from FL patients (Figure 1D). These results indicated that in FL, both $\mathrm{CD} 19^{+} \mathrm{B}$ cells and $\mathrm{CD} 11 \mathrm{c}^{+}$monocytes were able to produce IL-12, while in healthy individuals, CD $11 \mathrm{c}^{+}$ monocytes were the primary source of IL-12. Supporting this finding, serum IL-12 levels decreased in patients $(n=30)$ after rituximab therapy was given to deplete lymphoma B cells (Supplemental Figure 1A; supplemental material available online with this article; doi:10.1172/JCI59806DS1). These data indicate that lymphoma B cells play an important role in contributing to elevated IL-12 levels, especially in light of the fact that the frequency of CD $11 \mathrm{c}^{+}$ monocytes is low in FL biopsies (Supplemental Figure 1B).

Long-term culture with IL-12 in vitro impairs $C D 4^{+} T$ cell function. In addition to utilizing clinical specimens, we also measured the effect of long-term exposure to IL-12 in vitro on $\mathrm{T}$ cell function. It is well known that IL-12 induces IFN- $\gamma$ expression in T cells (33), and we confirmed that short-term incubation with IL-12 increased IFN- $\gamma$ production and slightly promoted intratumoral $\mathrm{T}$ cell proliferation in FL (Supplemental Figure 2, A and B). We also found that IL-12 inhibited the production of IL-2 and IL-17 in intratumoral T cells (Supplemental Figure 2B). IL-12 receptor consists of 2 subunits, IL-12R $\beta 1$ and IL-12R $\beta 2$, and coexpression of these 2 subunits is required for the generation of high-affinity IL-12binding sites. As shown in Supplemental Figure 2C, IL-12R $\beta 1$ was expressed on resting $\mathrm{T}$ cells at a low level, but was inducible upon activation of T cells. In contrast, IL-12R $\beta 2$ was constitutively expressed on intratumoral $\mathrm{T}$ cells and its expression was maintained on activated intratumoral cells. Similarly, IL-12R $\beta 2$ was constitutively expressed on peripheral blood T cells and its expression persisted on activated T cells. Again, IL-12R $\beta 1$ was expressed on resting $T$ cells at very low levels, but was inducible upon activation of T cells (Supplemental Figure 2D).

To determine the effect of long-term exposure to IL-12 on $\mathrm{CD}^{+}$ $\mathrm{T}$ cell function, we cultured freshly isolated $\mathrm{CD} 4^{+} \mathrm{T}$ cells from peripheral blood of healthy individuals in anti-CD3-coated plates in the presence or absence of IL-12 $(100 \mathrm{ng} / \mathrm{ml})$ and measured IL-2 and IFN- $\gamma$ production. Recombinant IL-2 $(20 \mathrm{ng} / \mathrm{ml})$ was added into medium to maintain $\mathrm{T}$ cell viability in this prolonged culture. As shown in Figure 1E, we again observed that short-term incuba- tion with IL-12 increased IFN- $\gamma$ production in $\mathrm{CD}^{+} \mathrm{T}$ cells compared with IL-12-untreated cells. Interestingly, at day $14, \mathrm{CD}^{+} \mathrm{T}$ cells began to lose their capacity to respond to IL-12 by upregulating IFN- $\gamma$ production. Similarly, long-term culture with IL-12 also inhibited T cell secretion of IL-2 (Figure 1E). Supporting these data, we found that despite elevated serum levels of IL-12 in FL patients and the ability of IL- 12 to promote $T_{H} 1$ cells, we were not able to observe an increased number of intratumoral $\mathrm{T}_{\mathrm{H}} 1$ cells in $\mathrm{FL}$ (Figure 1F). Furthermore, the number of intratumoral $\mathrm{T}_{\mathrm{H}} 17$ cells was significantly low in FL (Figure 1F), given that IL-12 inhibits $\mathrm{T}$ cell production of IL-17 induced by IL- 6 plus IL- $1 \beta$ (Supplemental Figure 2B). Since long-term culture would cause significant cell death, we wondered whether cell death may be the cause of IL-12induced $\mathrm{T}$ cell dysfunction. As shown in Supplemental Figure 2E, using annexin $\mathrm{V}(\mathrm{AnV})$ and propidium iodide (PI) staining, we observed that the number of dead cells $\left(\mathrm{AnV}^{+} \mathrm{PI}^{+}\right)$was below $15 \%$ on day 21. Although a significant number of T cells were apoptotic $\left(\mathrm{AnV}^{+} \mathrm{PI}\right)$ with a long-term culture, approximately $20 \%$ remained viable $\left(\mathrm{AnV}^{-} \mathrm{PI}^{-}\right)$on day 21 (Supplemental Figure $\left.2 \mathrm{E}\right)$. We therefore gated on viable cells when we analyzed the data (Supplemental Figure $2 \mathrm{~F}$ ). The data presented in Figure 1E show the result seen in the population of viable cells. These results suggested that long-term exposure to elevated IL-12 levels impaired T cell function, which may result in insufficient antitumor immunity in FL.

TIM-3-expressing $T$ cells are bighly represented and functionally exhausted in FL. To explore underlying mechanisms by which IL-12 impairs $\mathrm{T}$ cell function that may result in a detrimental outcome in FL patients, we determined the expression and function of TIM-3, expression of which has recently been shown to be associated with impaired $\mathrm{T}$ cell function and $\mathrm{T}$ cell exhaustion (23-27). We found that TIM-3 was highly expressed on a subset of T cells from PBMCs or LNs from FL patients, while its expression was negligible or moderate on T cells from control PBMCs or benign LNs, respectively (Figure 2, A and B). The number of TIM- $3^{+} \mathrm{T}$ cells accounted for approximately $32 \%$ and $39 \%$ of $\mathrm{CD} 4^{+}$or $\mathrm{CD}^{+} \mathrm{T}$ cells, respectively, in biopsy specimens and $6.2 \%$ and $6.7 \%$ in peripheral blood of FL patients (Figure 2, C and D), which was significantly higher than healthy tissue. We also determined TIM-3 expression on innate immune cells, since it has been shown that TIM-3 expression on innate immune cells plays a key role in promoting inflammation (34). Unlike T cells, we observed a similar expression pattern of TIM- 3 on innate immune cells in that TIM-3 was expressed on almost all $\mathrm{CD} 11 \mathrm{c}^{+}$or $\mathrm{CD} 14^{+}$cells from peripheral blood and biopsy specimens of healthy individuals and FL lymphoma patients (Figure 2, A and B), although the frequency of CD11c ${ }^{+}$or CD14 monocytes was significantly lower in biopsy specimens of FL lymphoma patients (Supplemental Figure 1B), suggesting that there was no difference in terms of TIM-3 expression on innate immune cells between healthy individuals and FL patients.

To functionally characterize TIM- $3^{+} \mathrm{T}$ cells, we first measured the proliferative capacity and cytokine production of intratumoral TIM- $3^{+} \mathrm{T}$ cells in FL. By CFSE staining, we found that TIM- $3^{+} \mathrm{CD} 4^{+}$ or $\mathrm{CD}^{+} \mathrm{T}$ cells exhibited a reduced ability to proliferate compared with TIM-3-CD4 ${ }^{+}$or $\mathrm{CD}^{+} \mathrm{T}$ cells in response to TCR activation (Figure 3A). Cytokine production was measured by intracellular staining in TIM- $3^{+}$or TIM-3- $3^{-} D 4^{+}$or $\mathrm{CD}^{+} \mathrm{T}$ cells stimulated with PMA/ion in the presence of brefeldin A for 4 hours. As shown in Figure 3B, there was less cytokine production by $\mathrm{TIM}-3^{+} \mathrm{CD} 4^{+}$ or $\mathrm{CD}^{+} \mathrm{T}$ cells than TIM-3-CD $4^{+}$or $\mathrm{CD}^{+} \mathrm{T}$ cells. The numbers of cytokine-producing (IL-2, IFN- $\gamma$, or IL- 17 by CD $4^{+} \mathrm{T}$ cells and IL-2, 
A

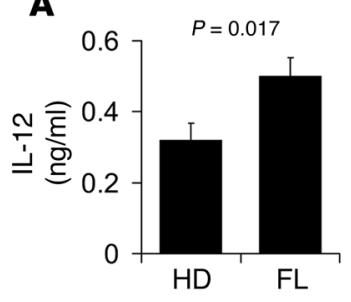

B

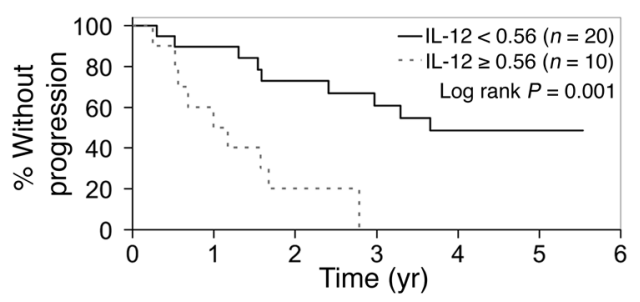

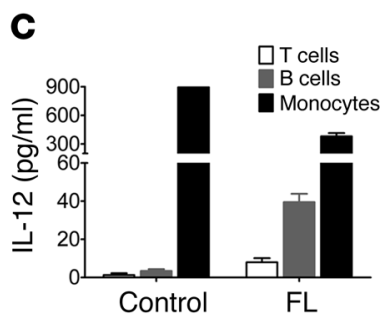

D
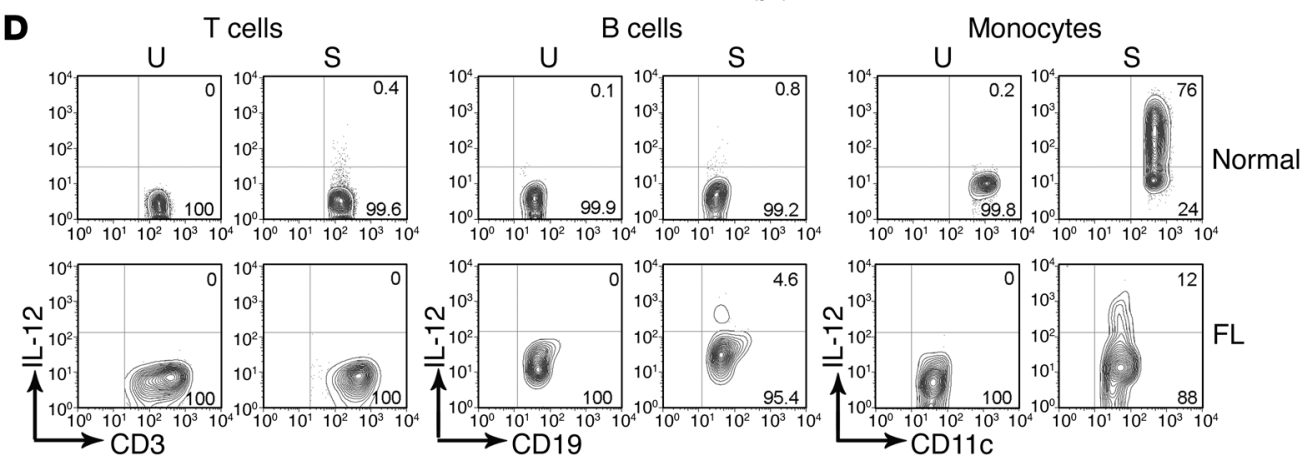

E
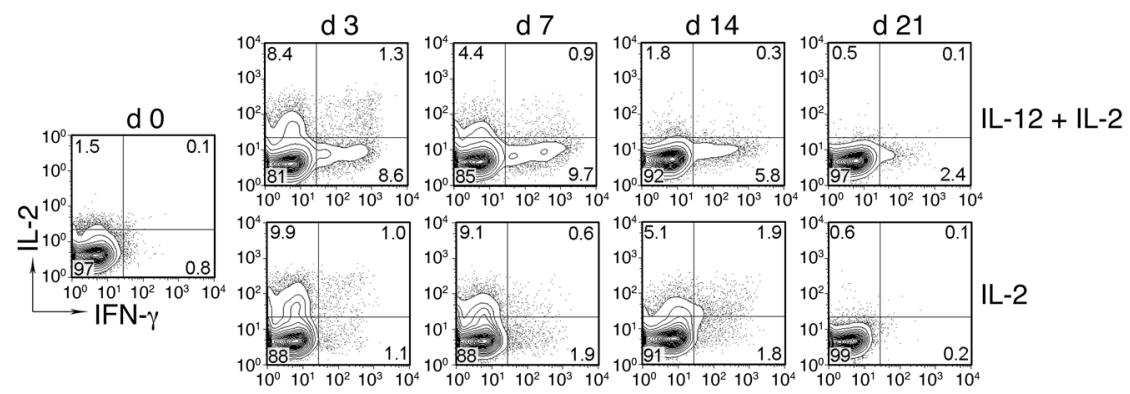

$\mathbf{F}$

$\mathrm{T}_{\mathrm{H}} 1$ cells
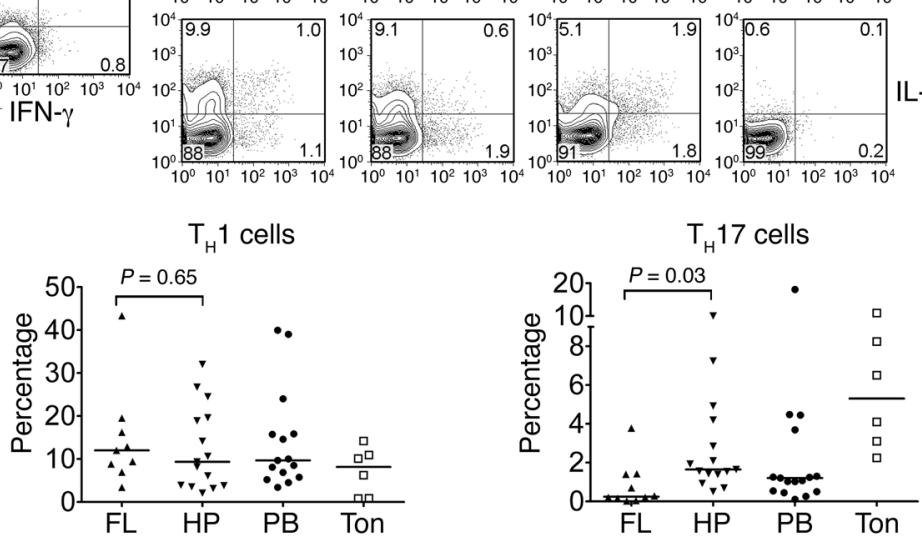

\section{Figure 1}

IL-12 serum levels and their correlation with survival in FL. (A) IL-12 serum levels in untreated FL patients (FL, average: $0.56 \pm 0.05 \mathrm{ng} / \mathrm{ml}, n=30$ ) and healthy donors (HD, average: $0.39 \pm 0.049 \mathrm{ng} / \mathrm{ml}, n=22, P=0.017$ ). IL-12 serum levels were measured by multiplex ELISA (Luminex). (B) A Kaplan-Meier curve for progression-free survival by serum levels of IL-12 in FL patients with a cutoff of $0.56 \mathrm{ng} / \mathrm{ml}(n=30)$. (C) Detection of the source of IL-12 levels measured by ELISA in culture supernatants of CD3 ${ }^{+}$T cells (white), CD19+ B cells (dark gray), or monocytes (black) treated with IFN- $\gamma$ plus LPS from healthy donors and FL patients. The figure shown is representative of 3 samples. (D) IL-12 production in subsets of T cells, B cells, and monocytes. Freshly isolated MCs from healthy individuals (upper panel) or FL patients (lower panel) were stimulated with (S) or without (U) IFN- $\gamma / \mathrm{LPS}$ and subjected to intracellular staining for IL-12 and surface staining for CD3, CD19, or CD11c. (E) Representative dot plots showing IL-2 and IFN- $\gamma$ production in CD4+ T cells treated with IL-12 (100 ng/ml) plus IL-2 $(20 \mathrm{ng} / \mathrm{ml})$ and IL-2 (20 ng/ml) alone at different time points $(n=3)$. Cells were incubated in anti-CD3-coated plates for the indicated times and then restimulated with PMA/ion in the presence of brefeldin $A$ for 5 hours. Cytokine production was measured by intracellular staining. Percentages of total cell numbers are indicated in $\mathbf{D}$ and E. (F) Frequency of $T_{H} 1$ and $T_{H} 17$ cells in biopsy specimens from FL, hyperplastic LNs (HP), peripheral blood from healthy donors (PB), and benign tonsil tissue (Ton). $T_{H} 1$ and $T_{H} 17$ cells were measured by flow cytometry and defined as CD4+IFN- $\gamma^{+}$and CD4 $4^{+} \mid \mathrm{L}-17^{+}$cells, respectively. Horizontal error bars indicate median expression levels.

IFN- $\gamma$, or granzyme B by CD8 ${ }^{+} \mathrm{T}$ cells) cells were higher in TIM-3$\mathrm{CD}^{+}$or $\mathrm{CD} 8^{+} \mathrm{T}$ cells compared with TIM- $3^{+} \mathrm{CD} 4^{+}$or $\mathrm{CD} 8^{+} \mathrm{T}$ cells (Figure 3B). Next, we determined whether cell signal transduction was also decreased in TIM- $3^{+} \mathrm{T}$ cells. $\mathrm{T}$ cells were treated with or without IFN- $\gamma$, IL-6, IL-12, or IL-2, respectively, and phosphorylation of STAT $1,-3,-4$, or -5 in TIM- $3^{-}$or TIM- $3^{+}$T cells was measured by Phosflow. We found that intratumoral TIM- $3^{+} \mathrm{T}$ cells had reduced cell signaling. Significantly less phosphorylation of 
A
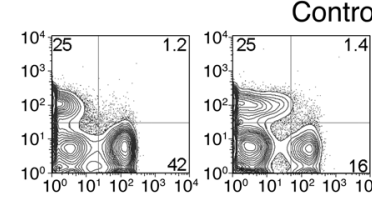

Control PBMCs

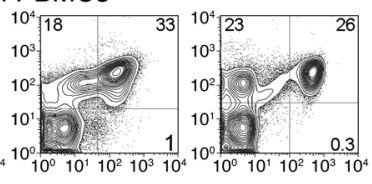

FL PBMCs

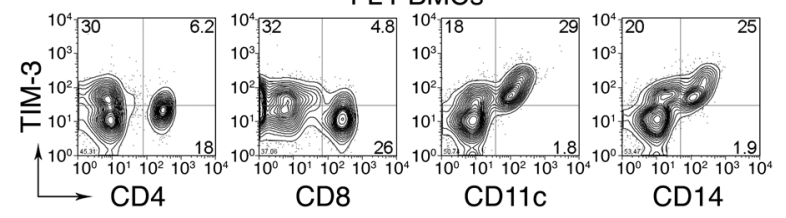

B

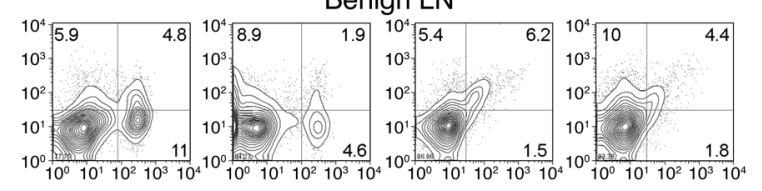

FL LN

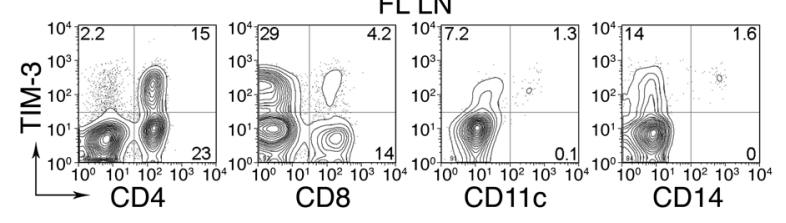

C

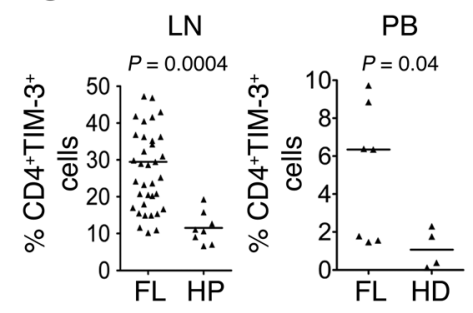

D

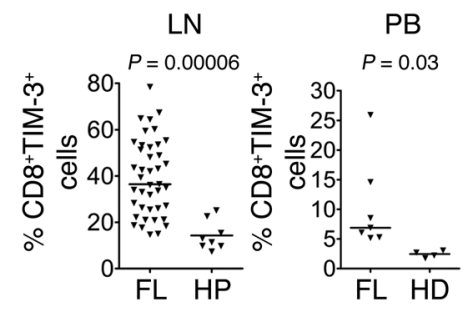

\section{Figure 2}

Frequency of TIM-3-expressing $T$ cells in FL. (A and B) Representative dot plots showing TIM-3 expression in $\mathrm{CD}^{+}, \mathrm{CD}^{+}$, $\mathrm{CD}_{11 \mathrm{C}^{+}}$, or $\mathrm{CD} 14^{+}$cells from peripheral blood $(\mathbf{A})$ or LNs $(\mathbf{B})$ from healthy individuals (upper panels) or FL patients (lower panels). Benign LN indicates LNs from patients with follicular hyperplasia. Percentages of total cell numbers are indicated. (C and D) A summary of frequency of TIM-3-expressing cells in $\mathrm{CD}^{+}{ }^{+}$(C) or $\mathrm{CD}^{+}$(D) T subsets from peripheral blood or $L N$ biopsy specimens from healthy donors (hyperplasia or healthy individual) or patients with FL. TIM- $3^{+} \mathrm{CD} 4^{+}$or $\mathrm{CD} 8+\mathrm{T}$ cells were measured by flow cytometry.
STAT1, -3 , or -4 (indicated by either MFI or percentage of positive cells from Phosflow staining) was seen in TIM- $3^{+} \mathrm{T}$ cells compared with TIM-3- T cells in response to cytokine stimulation (Figure 3, $\mathrm{C}$ and $\mathrm{D})$. Taken together, these results suggest that intratumoral TIM- $3^{+} \mathrm{T}$ cells in FL are functionally exhausted.

In order to distinguish whether intratumoral TIM- $3^{+} \mathrm{T}$ cells are exhausted or senescent, we measured CD28 expression on TIM- $3^{+}$ $\mathrm{T}$ cells, since loss of CD28 is seen with $\mathrm{T}$ cell senescence (35). We found that almost all TIM- $3^{+} \mathrm{T}$ cells were $\mathrm{CD} 28^{+} \mathrm{T}$ cells. The number of TIM $-3^{+} \mathrm{T}$ cells with CD28 loss was negligible, indicating TIM-3-expressing T cells are not senescent (Figure 3E). Furthermore, that decreased ability to produce cytokines was restored by IL-2 further suggested that TIM-3-expressing T cells were exhausted rather than senescent cells (data not shown). Intratumoral TIM- $3^{+} \mathrm{T}$ cells expressed CD45RO and lacked expression of CCR7 and CD62L, suggesting an effector rather than central memory phenotype (Figure 3E).

TIM-3 is coexpressed with PD-1 on intratumoral T cells in FL. TIM-3 was originally identified through a screen for $\mathrm{T}_{\mathrm{H}} 1$-specific markers and has since been found on other types of cells such as $\mathrm{CD}^{+} \mathrm{T}$ cells, $\mathrm{T}_{\mathrm{H}} 17$ cells, Tregs, monocytes, dendritic cells, mast cells, and microglia. To phenotypically characterize TIM- $3^{+} \mathrm{T}$ cells, we analyzed intratumoral TIM- $3^{+}$cells for expression of T-bet, GATA-3, ROR $\gamma t$, or Foxp3, and lineage markers for $T_{H} 1, T_{H} 2$, or $T_{H} 17$ cells or Tregs, respectively, in FL (36). A concomitant expression pattern of TIM-3 and T-bet was seen in a small population of $\mathrm{CD}^{+} \mathrm{T}$ cells in some FL biopsy samples, supporting the notion that TIM-3 is expressed by $\mathrm{T}_{\mathrm{H}} 1$ cells (Figure $4 \mathrm{~A}$ and Supplemental Figure 3). However, the finding that the majority of intratumoral TIM $-3^{+} \mathrm{T}$ cells lack expression of T-bet and that some T-bet ${ }^{+}$cells are not TIM- $3^{+} \mathrm{T}$ cells indicated that TIM-3 is not a specific marker for $\mathrm{T}_{\mathrm{H}} 1$ cells (Figure $4 \mathrm{~A}$ and Supplemental Figure 3 ). In most samples, TIM- $3^{+} \mathrm{T}$ cells lacked expression of CD25 and Foxp3, suggesting that $\mathrm{TIM}-3^{+} \mathrm{CD} 4^{+} \mathrm{T}$ cells were distinct from Tregs (Figure 4A,
Supplemental Figure 3 and data not shown). Although very few GATA- $3^{+}$and ROR $\gamma \mathrm{t}^{+} \mathrm{T}$ cells were present in FL samples, it appeared that TIM-3 was not expressed by intratumoral $\mathrm{T}_{\mathrm{H}} 2$ or $\mathrm{T}_{\mathrm{H}} 17$ cells (Figure 4A and Supplemental Figure 3).

It has been demonstrated that programmed death 1-expressing (PD-1-expressing) T cells are functionally exhausted in viral infection $(11,12)$ and tumors $(25,26)$. To phenotypically confirm functional exhaustion of TIM- $3^{+} \mathrm{T}$ cells, we determined whether intratumoral TIM- $3^{+} \mathrm{T}$ cells coexpressed PD- 1 in FL. We did find that TIM- $3^{+} \mathrm{CD}^{+}$or $\mathrm{CD}^{+} \mathrm{T}$ cells coexpressed PD-1 (Figure 4B). Supporting this finding, we observed that there was a strong correlation between $\mathrm{TIM}-3^{+} \mathrm{CD} 4^{+}$or $\mathrm{CD} 8^{+} \mathrm{T}$ cells and $\mathrm{PD}-1^{+} \mathrm{CD} 4^{+}$or $\mathrm{CD} 8^{+} \mathrm{T}$ cells, respectively (Figure 4C). However, we found that a population of PD $-1^{+} \mathrm{CD} 4^{+} \mathrm{T}$ cells in LNs of FL lacked TIM-3 expression. We further identified that this subset of cells was phenotypically consistent with follicular T helper cells $\left(\mathrm{T}_{\mathrm{FH}}\right)$, based on coexpression of CXCR5 and PD-1 (refs. 37-39 and Figure 4D), indicating that TIM-3 may be more specific as a marker for exhausted T cells in FL.

IL-12 induces TIM-3 expression on T cells independent of IFN- $\gamma$ production. The underlying mechanism mediating the regulation of TIM-3 expression and thereby contributing to increased numbers of TIM- $3^{+}$ T cells in FL is unknown. Given elevated serum levels of IL-12 in FL, we tested to determine whether IL-12 has an impact on TIM-3 expression on T cells. Freshly isolated T cells from peripheral blood of healthy individuals were cultured in anti-CD3-coated $(0.2 \mu \mathrm{g} / \mathrm{ml})$ plates in the presence or absence of increasing doses of IL-12 $(0-100 \mathrm{ng} / \mathrm{ml})$ or other cytokines for 3 days, and TIM-3 expression was detected by flow cytometry. Among several cytokines tested, IL-12 (100 ng/ml) was the only cytokine that strongly induced TIM-3 expression (Supplemental Figure 4A). T cells, including CD4 ${ }^{+}$and $\mathrm{CD}^{+}$subsets treated with IL-12, expressed TIM-3 in a dose-dependent manner (Figure 5A). Supporting this finding, blockade of IL-12 activity by a neutralizing IL-12 Ab attenuated the upregulation of TIM-3 expression (Supplemental Figure 4B). We found that neither the p35 
A

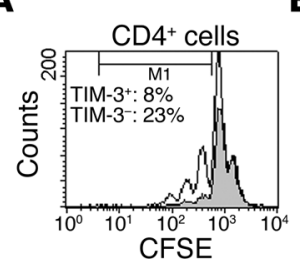

B CD4+ $T$ cells
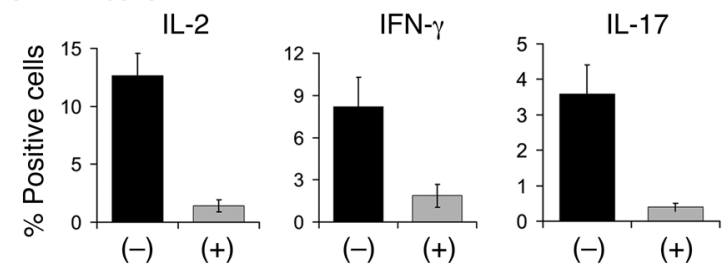

(+) $\mathrm{TIM}^{+} 3^{+}$

CD8 ${ }^{+} \mathrm{T}$ cells
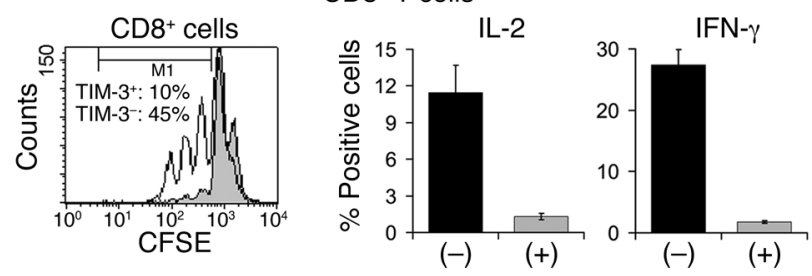

Stimulation with
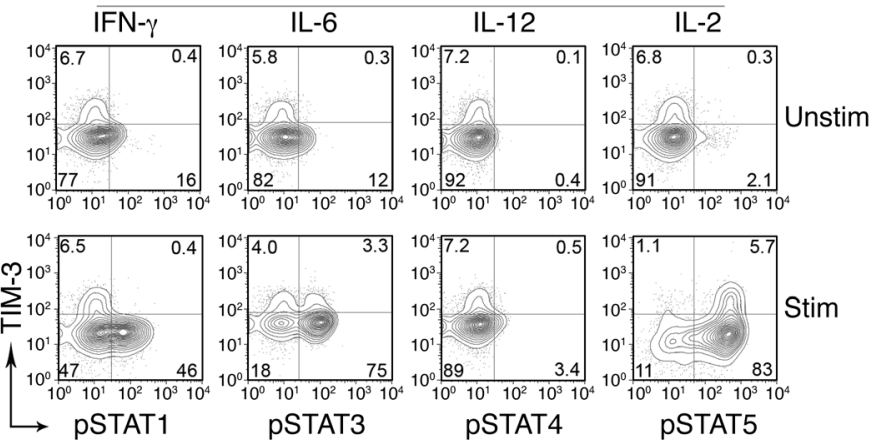

PSTAT4

pSTAT3

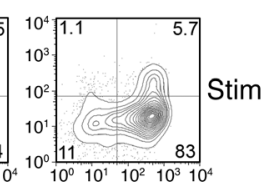

pSTAT5
D

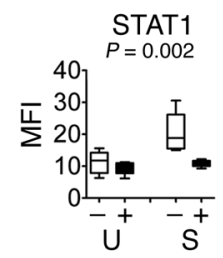

STAT1

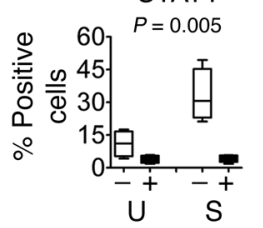

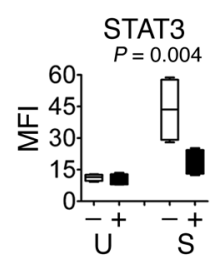

STAT3

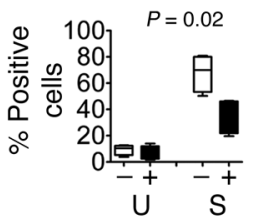

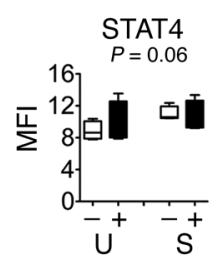

STAT4

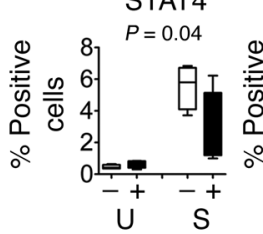

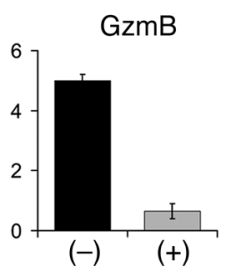

(-) TIM-3-

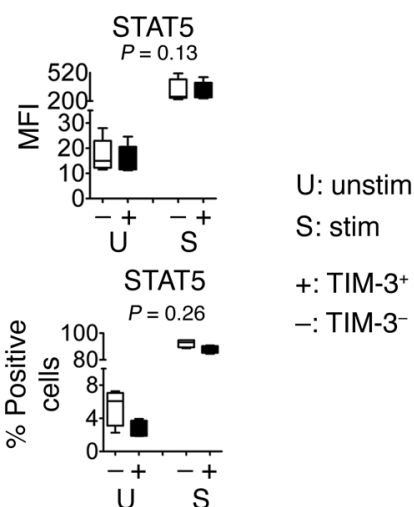

\section{Figure 3}

Function of TIM-3-expressing T cells in FL. (A) Histograms showing proliferation of TIM-3- (white) or TIM-3+ (gray) in $\mathrm{CD}^{+}$or $\mathrm{CD} 8^{+} \mathrm{T}$ cells. Proliferation was measured by CFSE staining and expressed as the number of CFSE dim cells. (B) A summary of cytokine production by TIM-3(black bars or minus signs) or TIM- $3^{+}$ (gray bars or plus signs) in $\mathrm{CD}^{+}$or $\mathrm{CD}^{+} \mathrm{T}$ cells. Cytokine production was measured by intracellular staining in intratumoral T cells stimulated with PMA/ion in the presence of brefeldin A $(n=4)$. (C) Representative dot plots showing phosphorylation of STATs in $\mathrm{TIM}^{-3^{+}}$or TIM-3$\mathrm{T}$ cells in FL. Freshly isolated MCs were treated with or without IFN- $\gamma$, IL-6, IL-12, or IL-2 and phosphorylation of STAT1, $-3,-4$, or -5 was measured by Phosflow staining. Plots shown were gated on $\mathrm{CD}^{+}$cells. (D) A summary of MFI (upper panel) or frequency (lower panel) of STATphosphorylated intratumoral TIM-3+ $(+)$ or $\mathrm{TIM}^{-} 3^{-}(-) \mathrm{CD}^{+} \mathrm{T}$ cells treated with $(\mathrm{S})$ or without (U) IFN- $\gamma$ (STAT1), IL-6 (STAT3), IL-12 (STAT4), or IL-2 (STAT5), respectively $(n=5)$. Phosphorylation of STATs in TIM-3or TIM- $3^{+} \mathrm{T}$ cells was measured by Phosflow staining and plots were gated on $\mathrm{CD}^{+}$cells. (E) Dot plots from a representative patient sample $(n=5)$ showing expression of CD28, CD45RO, CD62L, or CCR7 on $\mathrm{TIM}^{+/ /}$ $T$ cells. Percentages of total cell numbers are indicated in $\mathbf{C}$ and $\mathbf{E}$.

$\mathbf{E}$

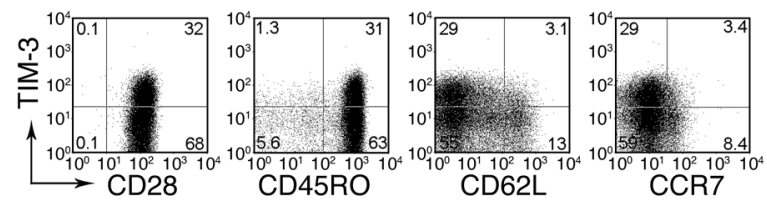

nor p40 subunits of IL-12, nor of IL-23, was able to induce TIM-3 expression, indicating that IL-12 p70 is essential to inducing TIM-3 expression (Supplemental Figure 4A). Although activation alone was capable of upregulating TIM-3 expression in a dose-dependent manner, addition of IL-12 further enhanced the upregulation of TIM-3 expression (Supplemental Figure 5, A and B).

To determine the biological relevance of IL-12-induced TIM-3 expression in FL, we tested the effect of endogenous IL-12 production by lymphoma B cells or macrophages stimulated through LPS/IFN- $\gamma$ on TIM-3 expression on intratumoral CD $4^{+} \mathrm{T}$ cells. We found that treatment of $\mathrm{CD}^{+}{ }^{+} \mathrm{T}$ cells alone with LPS/IFN- $\gamma$ had no effect on TIM-3 expression. However, when cocultured with lymphoma B cells or macrophages, LPS/IFN- $\gamma$ promoted TIM-3 expression on $\mathrm{CD}^{+} \mathrm{T}$ cells (Figure $5 \mathrm{~B}$ ). The administration of anti-IL-12 Abs to neutralize IL-12 activity attenuated LPS/IFN- $\gamma-$ induced TIM-3 expression in the presence of lymphoma B cells or macrophages, confirming the effect of IL-12 (endogenous production) on TIM-3 expression (Figure 5B). These results suggest the involvement of tumor or tumor microenvironment in inducing TIM-3 expression on intratumoral T cells. 


\section{A CD4+ T cells}
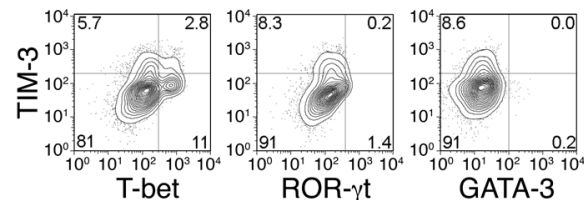

GATA-3

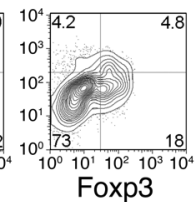

CD8 ${ }^{+} \mathrm{T}$ cells
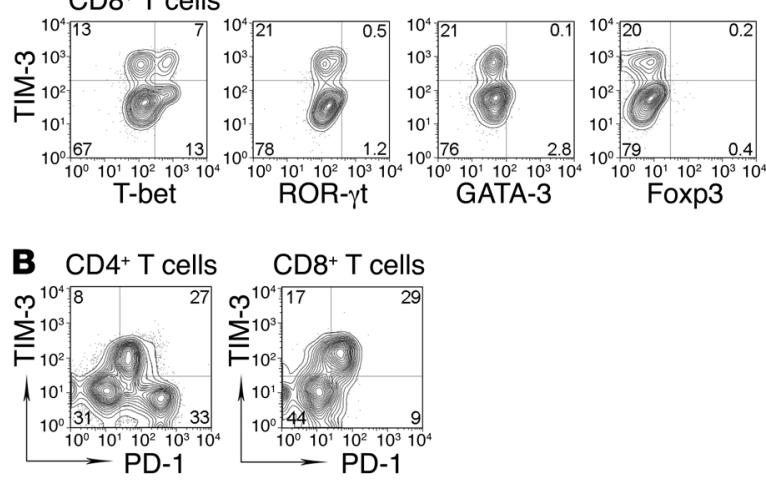

Figure 4

Coexpression of TIM-3 and PD-1 in FL. (A) Representative plots showing expression of T-bet, ROR $\gamma$ t, GATA-3, or Foxp3 in TIM-3- or TIM-3+ cells in $\mathrm{CD}^{+}$or $\mathrm{CD}^{+} \mathrm{T}$ cells in FL patients. Freshly isolated MCs were fixed, permeabilized, and stained for T-bet, ROR $\gamma \mathrm{t}$, GATA-3, or Foxp3 plus TIM-3, CD3, CD4, and CD8. (B) Dot plots showing expression of PD-1 and TIM-3 on CD4+ or CD8 ${ }^{+}$T cells from a representative LN biopsy of FL patients $(n=10)$. (C) Correlation analysis for CD4+PD-1+ (left) or CD8+PD-1+ (right) T cells with CD4+ or CD8+TIM-3+ T cells in FL patients. The frequency of CD4+PD-1+, CD8 ${ }^{+} \mathrm{PD}-1^{+}, \mathrm{CD} 4^{+} \mathrm{TIM}^{+} 3^{+}$, or $\mathrm{CD} 8^{+} \mathrm{TIM}-3^{+} \mathrm{T}$ cells was measured by flow cytometry. Percentages of total cell numbers are indicated in A, B, and D. (D) Dot plots showing expression of PD-1 and CXCR5 on TIM-3-expressing CD4+ (upper panels) or CD8+ (lower panels) T cells from a representative LN biopsy of FL patient $(n=10)$.

The activation of STAT4 and resultant upregulation of T-bet expression have become major events of IL-12 signaling in $\mathrm{CD}^{+}$ $\mathrm{T}$ cells (40). To test whether interruption of IL-12 signaling affects TIM-3 expression, we determined the effect of the blockade of T-bet and STAT4 on IL-12-mediated TIM-3 expression on CD $4^{+}$T cells isolated from peripheral blood of healthy individuals. By using a T-bet or STAT4 siRNA, we found that TIM-3 expression induced by IL-12 $(100 \mathrm{ng} / \mathrm{ml})$ was attenuated on $\mathrm{CD}^{+} \mathrm{T}$ cells transfected with either T-bet or STAT4 siRNA. As a control, transfection of CD4 $4^{+} \mathrm{T}$ cells with STAT5 siRNA had no effect on IL-12-induced TIM-3 expression (Figure 5C). In support of these data, treatment of $\mathrm{CD}^{+} \mathrm{T}$ cells with lisofylline, a chemical inhibitor of STAT4, decreased IL-12induced TIM-3 expression at a dose-dependent manner (Supplemental Figure 6A). These results confirmed the important role of IL-12 signaling pathway in TIM-3 induction on T cells.

Because of the ability of IL-12 to upregulate IFN- $\gamma$, we next determined whether IFN- $\gamma$ was involved in IL-12-induced TIM-3 expression on $\mathrm{CD}^{+} \mathrm{T}$ cells isolated from peripheral blood of healthy donors. Surprisingly, the addition of IFN- $\gamma$ or blockade of IFN- $\gamma$ by a neutralizing IFN- $\gamma$ Ab had no effect on the induction of TIM-3 expression on $\mathrm{CD}^{+}{ }^{+}$or $\mathrm{CD}^{+} \mathrm{T}$ cells (Supplemental Figure 4B and Supplemental Figure 6B), suggesting that IL-12-induced TIM-3 expression is independent of IFN- $\gamma$ production. Given that $\mathrm{PD}-1$-expressing $\mathrm{T}$ cells are functionally exhausted and TIM-3 is coexpressed with PD-1, we also determined whether IL-12 induces PD-1 expression on T cells. We found that IL-12 had no effect on PD-1 expression on T cells (data not shown).

To determine whether IL-12 induces TIM-3 expression on intratumoral $\mathrm{T}$ cells in FL in vivo, we correlated IL-12 serum levels and numbers of intratumoral TIM- $3^{+} \mathrm{T}$ cells in FL patients. We
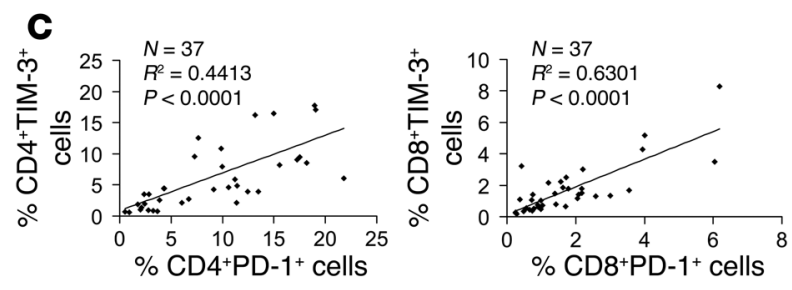

D
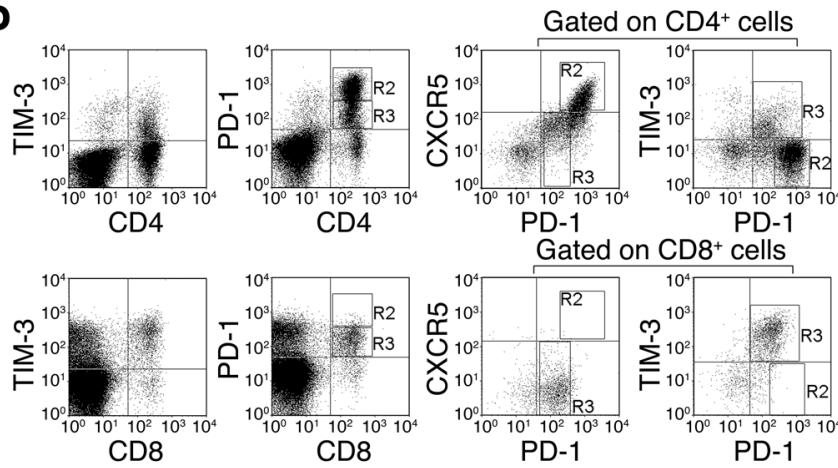

CD8
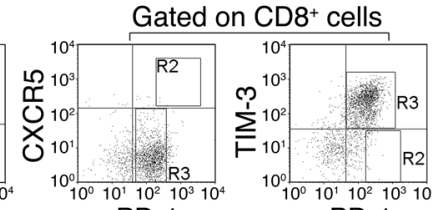

$\mathrm{PD}-1$ observed that there was a positive correlation between IL-12 serum levels and numbers of CD $4^{+} \mathrm{TIM}-3^{+} \mathrm{T}$ cells in FL patients, although the number of samples was limited (Figure 5D).

The blockade of TIM-3 signaling restores IL-12-mediated T-cell dysfunction. We have shown that long-term exposure to IL-12 leads to reduced $\mathrm{T}$ cell function. We also observed that intratumoral TIM- $3^{+} \mathrm{T}$ cells in FL displayed phenotypic and functional characteristics similar to those seen in $\mathrm{T}$ cell exhaustion. Furthermore, we found that IL-12 was the only cytokine capable of inducing TIM-3 expression on $\mathrm{T}$ cells. Based on these findings, we wanted to determine whether TIM-3 plays a role in IL-12-mediated dysfunction in T cells in FL. To do this, we determined whether blockade of TIM-3 signaling restored $\mathrm{T}$ cell dysfunction mediated by long-term exposure to IL-12. It has been shown that an anti-human TIM-3 $\mathrm{Ab}$ is able to block interaction of TIM-3 and its ligand, thereby interrupting TIM-3 signaling $(23,41)$. We measured the cytokine production by $\mathrm{CD}^{+} \mathrm{T}$ cells from peripheral blood of healthy individuals treated with or without anti-TIM-3 Ab (clone F38-2E2) at day 3 (short term) and day 10 (long term). As expected, IL-2 and IFN- $\gamma$ production in $\mathrm{CD}^{+} \mathrm{T}$ cells treated with IL-12 $(100 \mathrm{ng} / \mathrm{ml})$ plus an isotype $\mathrm{Ab}$ decreased over time, particularly when day 3 was compared with day 10 . Treatment with anti-TIM-3 Ab resulted in a slight initial decrease in IFN- $\gamma$ production in $\mathrm{CD}^{+} \mathrm{T}$ cells at day 3 , but the production of both IL- 2 and IFN- $\gamma$ in $\mathrm{CD}^{+} \mathrm{T}$ cells cultured in the presence of IL-12 and the anti-TIM-3 Ab at day 10 was maintained (Figure 6A). Supporting these data, the proliferation was also enhanced in T cells treated with anti-TIM-3 Abs (Figure 6B). These results indicated that TIM-3 signaling pathway was involved in $\mathrm{T}$ cell dysfunction mediated by longterm exposure to IL-12. 
A

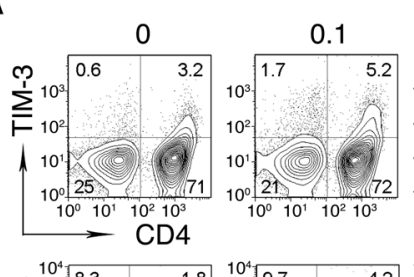

\section{$\mathrm{IL}-12(\mathrm{ng} / \mathrm{ml})$}
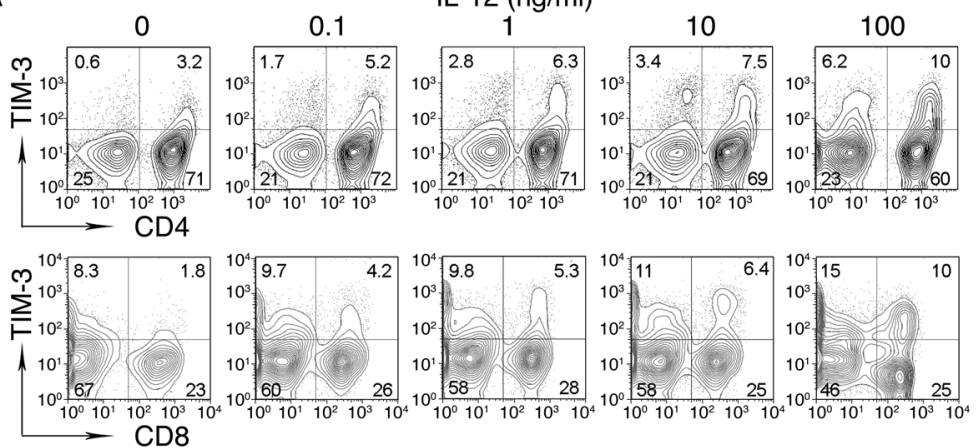

IFN- $\gamma /$ LPS

B

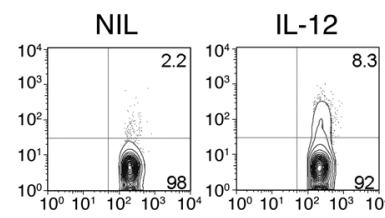

\section{LPS/IFN- $\gamma$}

+ anti-IL-12
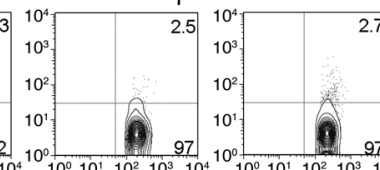

T cells

alone
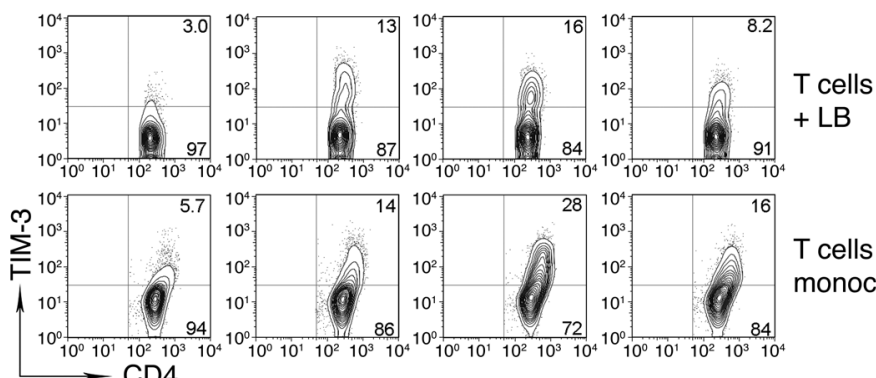

T cells + monocytes

C

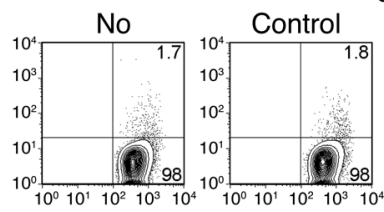

$\operatorname{siRNA}(100 \mathrm{ng} / \mathrm{ml})$
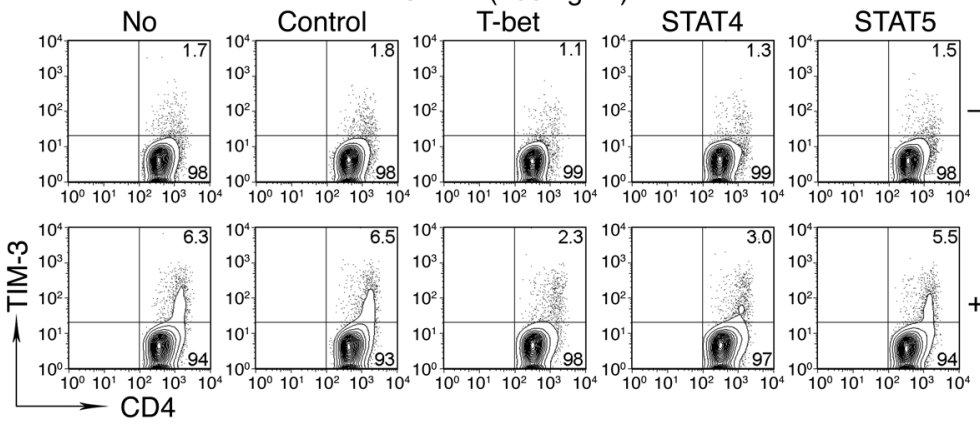

D

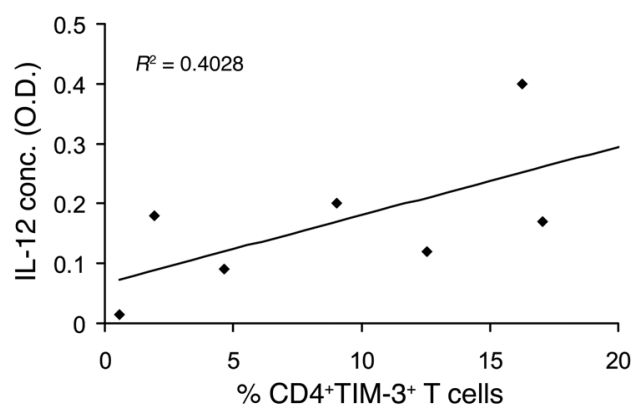

To further confirm this finding, we measured cytokine production in TIM-3- or TIM- $3^{+}$T cells treated with without anti-TIM-3Ab at day 3 (short term) and day 10 (long term). As shown in Figure $6 \mathrm{C}$, TIM $-3^{+} \mathrm{CD} 4^{+} \mathrm{T}$ cells were the major population of IL-2- or IFN- $\gamma$-expressing cells in the presence of IL-12. Long-term culture with IL-12 led to the inability of $\mathrm{TIM}-3^{+} \mathrm{CD} 4^{+} \mathrm{T}$ cells to produce

\section{Figure 5}

Effect of IL-12 on TIM-3 expression on T cells in FL. (A) Effect of IL-12 on TIM-3 expression in CD4+ (upper panel) or CD8+ (lower panel) T cells. T cells were cultured in OKT3-coated $(0.2 \mu \mathrm{g} / \mathrm{ml})$ plates with anti-CD28 Abs in the presence or absence of a series of doses of IL-12 for 3 days. TIM-3 expression was measured by flow cytometry $(n=10)$. (B) Representative dot plots showing TIM-3 expression on CD4 ${ }^{+} \mathrm{T}$ cells cocultured either alone (upper panel) or with lymphoma B cells (middle panel) or monocytes (lower panel) in the presence or absence of IL-12, LPS, or LPS/IFN- $\gamma$ alone or combined with a neutralizing anti-IL-12 Ab $(n=3)$. (C) Representative dot plots showing TIM-3 expression on CD4 ${ }^{+} \mathrm{T}$ cells transfected with siRNA for T-bet, STAT4, or STAT5 in the presence (lower panel) or absence (upper panel) of IL-12 $(n=4)$. Mock transfection or transfection with scrambled siRNA was used as a control. Percentages of total cell numbers are indicated. (D) A scatter graph showing a correlation between IL-12 serum levels and numbers of CD4 ${ }^{+}$TIM $-3^{+} \mathrm{T}$ cells in FL patients prior to treatment. IL-12 serum levels and numbers of CD4 ${ }^{+}{ }^{T I M}-3^{+} \mathrm{T}$ cells in the total MC population of FL specimens were measured by multiplex ELISA and flow cytometry, respectively.

cytokines. However, interruption of the TIM-3 signaling pathway using the blocking Abs prevented TIM- $3^{+} \mathrm{CD} 4^{+} \mathrm{T}$ cells from IL-12-mediated failure to produce cytokines. The number of IL-2- or IFN- $\gamma$-expressing cells was significantly higher in the subsets of TIM $-3^{+} \mathrm{CD} 4^{+} \mathrm{T}$ cells treated with anti-TIM-3 Abs compared with isotype control at day 10 (Figure 6D). These results were consistent with the finding that this Ab blocks interaction of TIM-3 and its ligand and confirmed that TIM-3 signaling plays a crucial role in $\mathrm{T}$ cell dysfunction mediated by long-term exposure of IL- 12 .

Elevated numbers of TIM $-3^{+}$T cells correlate with poor outcome in FL. As a result of the presence in FL lymphoma of substantial numbers of TIM $-3^{+} \mathrm{T}$ cells that are functionally exhausted, we predicted that intratumoral TIM $-3^{+} \mathrm{T}$ cells would adversely affect patient outcomes. Using tumor samples from FL patients, which commonly contain a significant number of $\mathrm{T}$ cells (Supplemental Figure 7A), we found that these biopsy specimens contained considerable numbers of TIM $-3^{+} \mathrm{CD} 4^{+} \mathrm{T}$ cells, accounting for a median of $4.4 \%$ (range: $0.57 \%-21.14 \%$ ) of intratumoral MCs (Supplemental Figure 7B). These cells represented a greater proportion of the intratumoral MCs than other cells shown to affect antitumor immunity in FL, such as $\mathrm{CD} 4{ }^{+} \mathrm{CD} 25^{+}$Tregs, which accounted for a median of $2.9 \%$ (range: $0.45 \%-16.3 \%$ ) of MCs (Supplemental Figure 7C). We observed that the numbers of TIM- $3^{+}$cells, CD $4^{+} \mathrm{TIM}^{-} 3^{+}$ $\mathrm{T}$ cells, or $\mathrm{CD} 8^{+} \mathrm{TIM}-3^{+} \mathrm{T}$ cells were associated with a higher histological grade (Figure 7A) and higher serum lactate dehydrogenase 
A

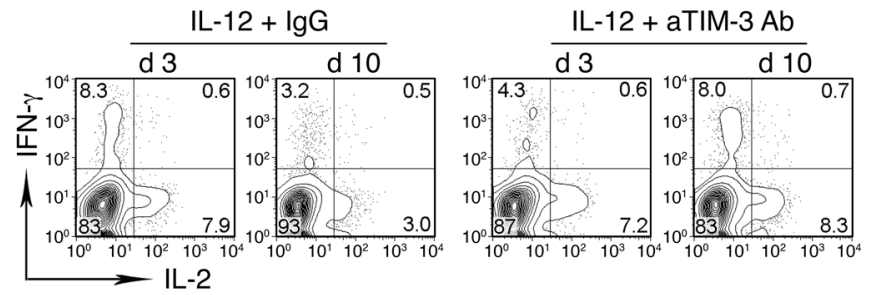

B
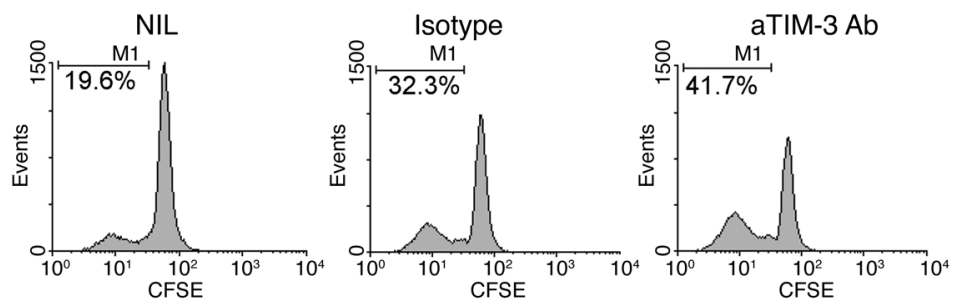

C
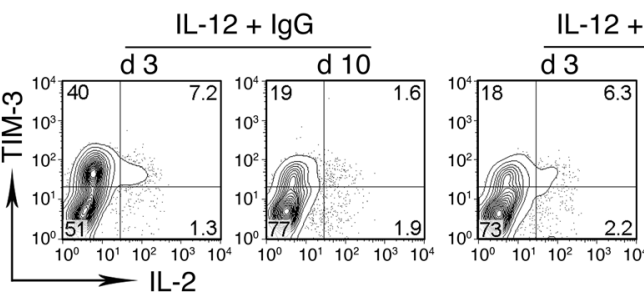

$\frac{\mathrm{IL}-12}{\mathrm{~d} 3}$
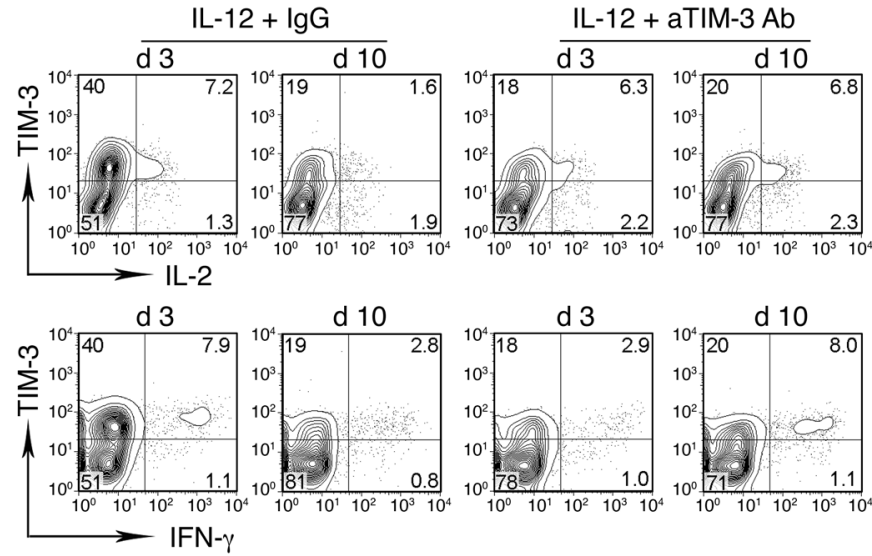

D

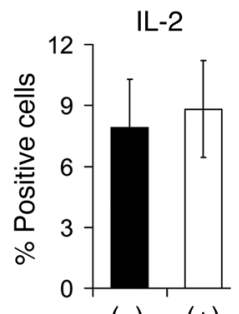

$(-) \quad(+)$
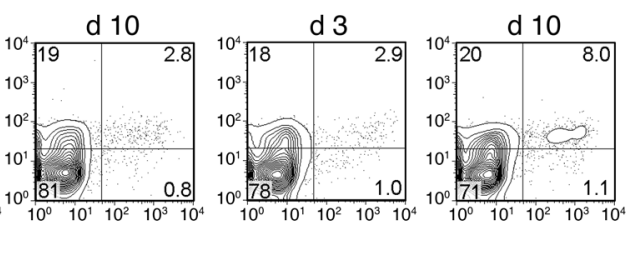

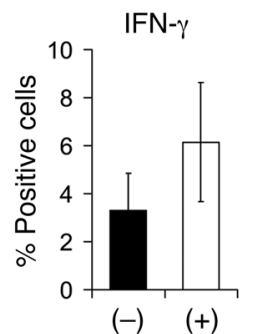

$(-) \quad(+)$

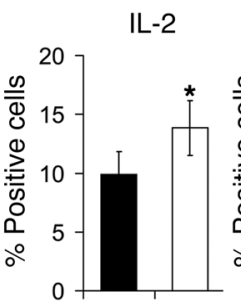

$(-) \quad(+)$

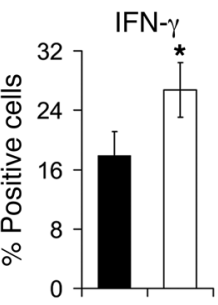

$(-) \quad(+)$

TIM- $3{ }^{+}{ }^{+C D} 4{ }^{+} T$ cells

\section{Figure 6}

Effect of blockade of TIM-3 signaling on restoration of IL-12-mediated T cell dysfunction. (A) Representative dot plots showing IL-2 and IFN- $\gamma$ production in CD4+ $T$ cells treated with either anti-TIM-3 Ab or isotype IgG in the presence of IL-12 at different time points $(n=5)$. IL-2 and IFN- $\gamma$ production were detected by intracellular staining. (B) Representative histograms showing proliferation of $\mathrm{CD} 4^{+} \mathrm{T}$ cells treated with or without anti-TIM-3 Abs or isotype IgG control. Proliferation was measured by CFSE staining and expressed as the number of CFSEdim cells. (C) Representative dot plots showing IL-2 (upper panels) and IFN- $\gamma$ (lower panels) production in TIM-3- or TIM $-3^{+} \mathrm{CD} 4^{+} \mathrm{T}$ cells treated with either anti-TIM-3 Abs or isotype IgG in the presence of IL-12 at different time points $(n=5)$. IL-2 and IFN- $\gamma$ production were detected by intracellular staining. Percentage of total cell numbers are indicated $(\mathbf{A}$ and $\mathbf{C})$. (D) A summary of frequency of IL-2- or IFN- $\gamma$-producing cells in TIM-3- or TIM-3+ $3^{+} 4^{+} \mathrm{T}$ cells treated with either anti-TIM-3 Ab (+) or isotype $\operatorname{IgG}(-)$ in the presence of IL-12 for 10 days $(n=5)$. IL-2 or IFN- $\gamma$ production in TIM-3- or TIM- $3^{+}$CD $4^{+}$ T cells was measured by intracellular staining and calculated as percentage of total $\mathrm{CD} 4^{+}$cells. Data are shown as mean \pm SD. ${ }^{*} P<0.05$.
(LDH) levels (Figure 7B) in FL patients. Furthermore, the frequency of TIM- $3^{+}$cells as well as CD $4^{+} \mathrm{TIM}-3^{+} \mathrm{T}$ cells significantly correlated with poorer survival in FL patients (Figure 7C). Although PD- 1 was coexpressed and correlated with TIM- 3 on T cells, the numbers of $\mathrm{CD} 4^{+} \mathrm{PD}-1^{+}$or $\mathrm{CD} 8^{+} \mathrm{PD}-1^{+} \mathrm{T}$ cells were not associated with survival in FL patients (Figure 7D).

\section{Discussion}

It is well established that IL-12 induces IFN- $\gamma$ production by $\mathrm{T}$ and NK cells and promotes $T_{H} 1$ cell development. Given that IFN- $\gamma$ is critical for the effective activation and engagement of cellular components of the innate and adaptive immune systems $(42,43)$, IL-12 has been intensively studied as an agent to boost immune response since it was identified in approximately 1990. In the context of tumors, IL-12 has been investigated as an antitumor agent in mouse models with a variety of types of tumors and displays antitumor properties that are mainly mediated by IFN- $\gamma$ secretion by
$\mathrm{CD} 4^{+} \mathrm{T}$ cells, $\mathrm{CD} 8^{+} \mathrm{T}$ cells, and NK cells. However, administration of IL-12 to advanced solid tumors and hematologic malignancies as either monotherapy or in combination with other therapies has resulted in a very limited clinical benefit, with an objective response rate ranging between $0 \%$ and $11 \%$ (19). In FL, the administration of IL-12 to boost antitumor immunity has shown an inferior, instead of a superior, clinical benefit. Data from a clinical trial of IL-12 in combination with rituximab in FL showed a lower response rate in patients treated with the combination than in patients treated with rituximab alone (20). Supporting this observation, we have found that elevated serum levels of IL-12 before treatment were associated with a poor prognosis in FL patients. These results strongly indicate that IL-12 plays a detrimental role in FL. In fact, we observed in vitro that while IL-12 induces IFN- $\gamma$ expression in $\mathrm{CD}^{+} \mathrm{T}$ cells at short-term culture, long-term exposure to IL-12 results in $\mathrm{CD} 4^{+} \mathrm{T}$ cells losing the ability to produce IFN- $\gamma$, suggesting an impairment of immune response mediated by IL-12. 


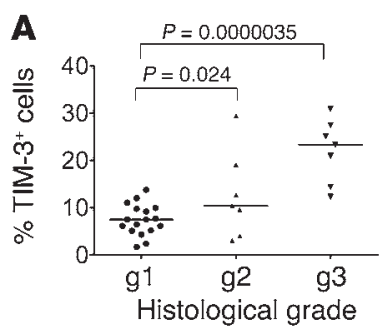

B
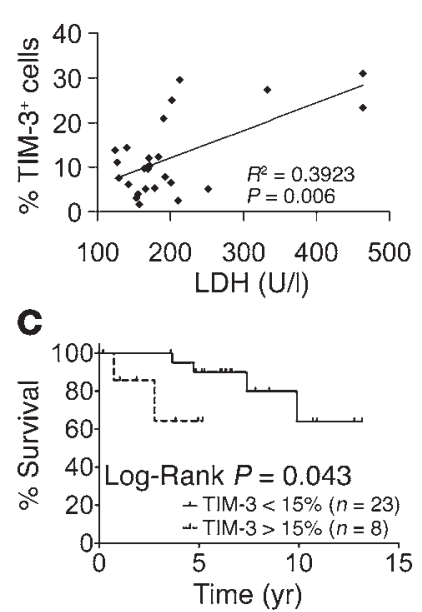

D

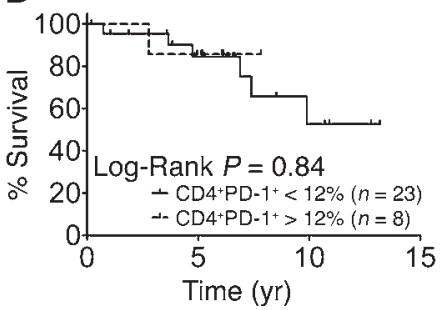

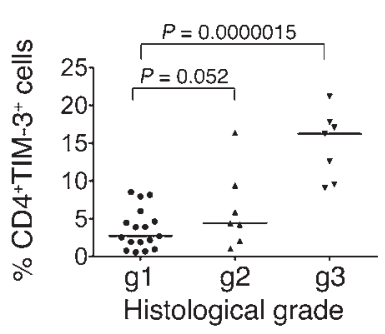
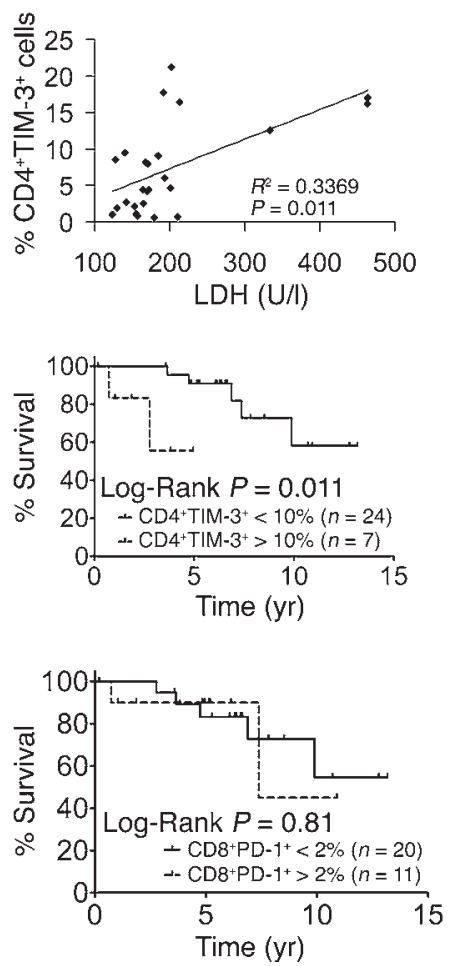
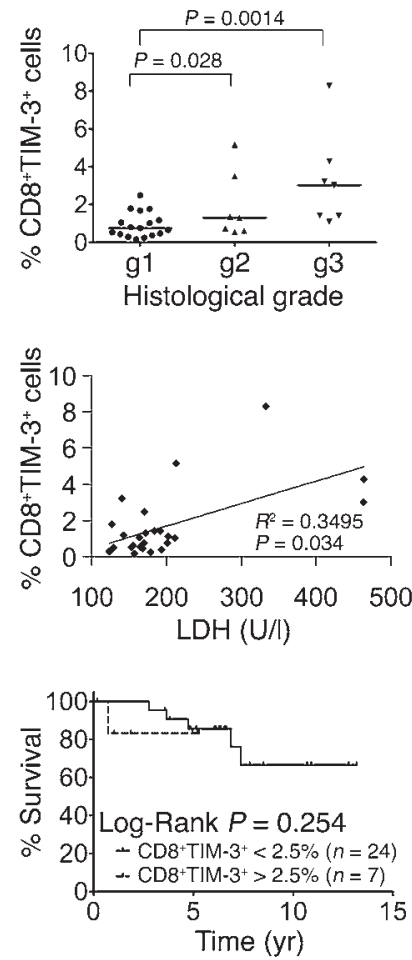

Figure 7

Correlation of TIM-3-expressing cells with clinical survival in FL patients. (A and B) Correlation of the numbers of total TIM-3+ cells (left), CD4+TIM-3+ T cells (middle), or CD8+TIM-3+ (right) T cells with histological grade (H1-3) $(\mathbf{A})$ or LDH levels $(\mathbf{B})$ in FL patients $(n=31)$. (C) KaplanMeier curves for progression-free survival of FL patients $(n=31)$ by the number of TIM- $3^{+}$cells (left), CD4+TIM-3+ T cells (middle), or CD ${ }^{+}{ }^{+}$TIM-3 ${ }^{+}$ T cells (right) with a cutoff of $15 \%, 10 \%$, or $2.5 \%$, respectively. (D) Kaplan-Meier curves for progression-free survival of FL patients ( $n=31)$ by the number of CD4+PD-1+ T cells (left) or CD8+PD-1+ T cells (right) with a cutoff of $12 \%$ or $2 \%$, respectively. The numbers of subsets represent the frequency in the total MC population from FL specimens.

It is completely unknown what underlying mechanisms are involved in IL-12-mediated impairment of $\mathrm{T}$ cell function that may result in an inferior effect in FL patients. Our study shows that IL-12 induces $\mathrm{T}$ cell dysfunction by upregulating TIM-3 expression on intratumoral $\mathrm{T}$ cells, thereby contributing to its detrimental role in FL. TIM-3, a family member of T cell immunoglobulin and mucin domain proteins, was originally identified as a marker for $\mathrm{T}_{\mathrm{H}} 1$ cells. It has been recently shown that TIM-3 expression impairs $\mathrm{T}$ cell function and leads to $\mathrm{T}$ cell exhaustion in viral infections $(23)$ and tumors $(25,26)$. We saw a significantly increased number of T cells expressing TIM-3 present in FL that displayed reduced cell signaling and function, suggesting the involvement of TIM-3 in T cell exhaustion in lymphoma. Supporting this, we found that TIM-3 was expressed on multiple T cell subsets in addition to $\mathrm{T}_{\mathrm{H}} 1\left(\mathrm{CD}^{+} \mathrm{T}^{-}\right.$-bet $\left.^{+}\right)$cells. Furthermore, TIM-3 is coexpressed with PD-1, a marker for exhausted T cells. More importantly, the increased numbers of $\mathrm{TIM}-3^{+} \mathrm{T}$ cells are associ- ated with a more aggressive histological phenotype and reduced survival in FL. Expression of TIM-3 has previously been reported in lymphoma specimens and is also expressed on endothelial cells, thereby facilitating lymphoma progression (44).

This raised the question of whether intratumoral TIM- $3^{+} \mathrm{T}$ cells from FL are functionally exhausted or replicatively senescent, since both conditions share common features, such as decreased immune function. However, the 2 processes actually differ in many aspects. Phenotypically, loss of CD28 expression is a significant feature of senescent $T$ cells $(35,45)$, although shortening of telomeres is also a key characteristic of senescence (46). In contrast, increased expression of PD-1 and TIM-3, as shown in the present study, is associated with exhausted T cells. Exhausted T cells display an effector memory cell phenotype and express low levels of L-selectin (CD62L) and CCR7 (35). Our findings therefore strongly suggest that intratumoral TIM- $3^{+} \mathrm{T}$ cells in lymphoma exhibit an exhausted rather than a senescent phenotype. 
The underlying mechanism for the significantly high percentage of TIM- $3^{+} \mathrm{T}$ cells in FL is unknown. Given that IL-12 strongly induces TIM-3 expression on T cells, elevated serum levels of IL-12 may be responsible for the existence of highly represented TIM- $3^{+} \mathrm{T}$ cells. This is supported by the finding that serum levels of IL-12 correlate with the number of TIM- $3^{+}$T cells in FL. To determine the underlying mechanism by which IL-12 induces TIM-3 expression, we measured the involvement of IFN- $\gamma$ production (the main product of IL-12), STAT4 phosphorylation (the main component of the IL-12 signaling pathway), and T-bet expression (the main downstream target of the IL-12 signaling pathway) in IL-12-mediated TIM-3 expression. Our results clearly show that STAT4 and T-bet expression are involved in IL-12-mediated TIM-3 induction because the blockade of STAT4 and T-bet expression results in an inability of IL-12 to induce TIM-3 expression, which is consistent with previous work suggesting that T-bet regulates TIM-3 expression (47). In contrast, IFN- $\gamma$ production is not involved in IL-12-mediated TIM-3 induction, based on the findings that exogenous addition of IFN- $\gamma$ or inhibition of IFN- $\gamma$ activity has no effect on IL-12-mediated TIM-3 expression. A recent study suggests that IL-12-mediated effects, such as upregulation of T-bet expression, are often through an IFN- $\gamma$-independent mechanism (48), which is in agreement with our findings.

We found that TIM-3 expression is not limited to CD4 ${ }^{+}$T-bet ${ }^{+}$ $\mathrm{T}$ cells in lymphoma specimens and that the blockade of T-bet expression results in an inability of IL-12 to induce TIM-3 expression. It appears that T-bet is required for the in vitro effects of IL-12 on TIM-3 expression, but may be dispensable for TIM-3 expression on $\mathrm{CD}^{+} \mathrm{T}$ cells in vivo. While the underlying mechanism leading to these differences between in vitro and in vivo data is unclear, the findings from other studies may provide a partial explanation. For instance, although IL-12 is the only cytokine among the many cytokines we tested that can upregulate TIM-3 expression, other cytokines such as IL-4 (49) or pathophysiological conditions such as pregnancy (49), inflammation (50), infection (23), and carcinogenesis (26), are also involved in TIM-3 upregulation on T cells. The other conditions are often present in lymphoma patients and may contribute to TIM-3 expression.

In conclusion, we have demonstrated in FL that IL-12, in contrast with its role in augmenting the immune response through IFN- $\gamma$, induces T cell exhaustion by upregulating TIM-3 expression independently of IFN- $\gamma$ induction. We further demonstrated that lymphoma B cells produce IL-12, thereby contributing to $T$ cell exhaustion by promoting TIM-3 expression on intratumoral T cells. Impairment of antitumor immunity due to T cell exhaustion induced by the IL-12/ TIM-3 pathway may account for the observation that high levels of serum IL-12 and increased numbers of TIM- $3^{+} \mathrm{CD} 4^{+} \mathrm{T}$ cells correlate with a worse outcome in FL patients. These findings not only reveal a IL-12/TIM-3 pathway that plays an important role in impairing tumor immunity and detrimentally affecting prognosis in FL patients, but may have therapeutic potential for cancer patients in that IL-12-mediated T cell exhaustion could be targeted.

\section{Methods}

Patient samples. Patients providing written informed consent were eligible for this study if they had a tissue biopsy that on pathologic review showed FL and adequate tissue or peripheral blood to perform the experiments. PBMCs from healthy donors and LNs from patients with hyperplasia were used as controls.

Cell isolation and purification. Fresh tumor biopsy specimens from patients with FL and control LNs were gently minced over a wire mesh screen to obtain a cell suspension. The cell suspension or peripheral blood from patients or healthy donors was centrifuged over Ficoll-Hypaque at $500 \mathrm{~g}$ for 15 minutes to isolate MCs. CD3 ${ }^{+} \mathrm{T}$ cells, $\mathrm{CD} 14^{+}$monocytes, or $\mathrm{CD} 19^{+}$ $\mathrm{B}$ cells were isolated using positive selection with CD3, CD14, or CD19 microbeads (Miltenyi Biotec). $\mathrm{CD} 3^{+} \mathrm{TIM}-3^{+}$or TIM-3- $\mathrm{T}$ cells were isolated by $\mathrm{CD} 3$-negative selection, and the resulting $\mathrm{CD}^{+} \mathrm{T}$ cells were incubated with biotin-conjugated TIM-3 Ab followed by incubation with streptavidin-conjugated microbeads.

Intracellular staining and flow cytometry. Intracellular staining was performed following the manufacturer's instructions and cells were analyzed on a flow cytometer. For profiling of cytokine production by TIM- $3^{+}$or TIM-3- T cells, freshly isolated MCs were stimulated with PMA/ion in the presence of protein transport inhibitor brefeldin A for 5 hours. For cytokine production by IL-12-induced TIM-3 $3^{+} \mathrm{T}$ cells, $\mathrm{CD}^{+} \mathrm{T}$ cells were cultured in anti-CD3-coated plates (BD Biosciences) with anti-CD28 Abs (BD Biosciences) in the presence or absence of IL-12 for 3 days. For IL-12 production by cell subsets, cells were treated with or without IFN- $\gamma$ for 2 hours and then LPS for another 22 hours. Cells were stimulated with PMA/ion in the presence of brefeldin A for 5 hours. After fixation and permeabilization, cells were stained with fluorochrome-conjugated Abs for IL-17, IL-2, IL-12, granzyme B, or IFN- $\gamma$ plus surface marker Abs for CD4, CD8, CD11c, or CD19 in each specimen.

Transcriptional factor expression detection. T-bet, GATA-3, ROR $\gamma \mathrm{t}$, and Foxp3 expression were determined by flow-based intracellular staining following the manufacturer's instructions. Cells were fixed and permeabilized with reagents from a Foxp3-staining kit (BioLegend). Cells were then stained with fluorochrome-conjugated Abs against T-bet, GATA-3, ROR $\gamma \mathrm{t}$, or Foxp3 plus fluorochrome-conjugated anti-CD4, CD8, and TIM-3 Abs for 30 minutes and analyzed by flow cytometry.

CFSE labeling and Tcell proliferation assay. $\mathrm{CD}^{+} \mathrm{T}$ cells were washed, counted, and resuspended at $1 \times 10^{7} / \mathrm{ml}$ in PBS. A stock solution of CFSE $(5 \mathrm{mM})$ was diluted 1:100 with PBS and added to the cells for a final concentration of $5 \mu \mathrm{M}$. After 10 minutes at room temperature, cells were washed 3 times with 10 volumes of PBS containing $10 \%$ FBS. CFSE-labeled T cells were cultured on OKT3-coated $(0.2 \mu \mathrm{g} / \mathrm{ml}) 96$-well plates at $37^{\circ} \mathrm{C}$ in the presence of $5 \% \mathrm{CO}_{2}$. Cells were harvested at day 3 , washed, and stained with $\mathrm{PE}$-anti-CD3 for 30 minutes at $4{ }^{\circ} \mathrm{C}$. Cells were washed twice and acquired and analyzed on a flow cytometer.

Luminex and ELISA assay. The concentration of IL-12 in serum or culture supernatants was measured by Luminex (Invitrogen) or ELISA (R\&D Systems), respectively. Serum was collected from FL patients before or after treatment with rituximab. Supernatants were harvested from the culture of $\mathrm{T}$ cells, B cells, or monocytes stimulated with or without IFN- $\gamma$ for 2 hours and then LPS for another 22 hours. For the Luminex assay, the serum specimens were thawed, clarified by centrifugation, and assayed according to kit instruction. The specimens were analyzed on a Luminex 200 instrument and results generated using STarStation software. For ELISA, supernatants were collected from the culture of cells and assayed according to the manufacture's instructions. The optical density of each well was determined using a SpectraMax 190 microplate reader (Molecular Devices) set to $450 \mathrm{~nm}$ and analyzed using SoftMax Pro 5 software.

TIM-3 expression detection. TIM-3 expression on different cell types was examined by flow cytometry. Cells were stained with anti-TIM-3-PE or APC (R\&D systems) plus fluorochrome-conjugated anti-CD3, CD4, CD8, CD11c, CD14, CD19, or PD-1 Abs to quantify TIM-3-expressing subsets. For TIM-3 induction, T cells were cultured in OKT3-coated $(0.1-1 \mu \mathrm{g} / \mathrm{ml})$ plates with anti-CD28 Abs in the presence or absence of indicated stimuli for 3 days. To minimize effect of activation on TIM-3 induction, T cells were cultured in OKT3-coated $(0.2 \mu \mathrm{g} / \mathrm{ml})$ plates in most experiments. 
Phosphorylation assay. The phosphorylation of STATs was detected following the manufacturer's instructions (BD Biosciences). Briefly, freshly isolated MCs were stimulated with or without PMA/ion or cytokines for 30 minutes and then fixed and permeabilized using a Phosflow Kit (BD Biosciences). Cells were stained with anti-STAT1, or STAT3, STAT4, or STAT5-Alexa Fluor 647 Abs plus anti-CD3-FITC and TIM-3-PE Abs for 30 minutes and analyzed by flow cytometry.

siRNA transfection. Transfection of $\mathrm{CD}^{+}{ }^{+} \mathrm{T}$ cells with siRNA was performed according to the manufacturer's instructions (QIAGEN). GeneSolution siRNA and HiPerFect Transfection Reagent were purchased from QIAGEN. Then $100 \mathrm{nM}$ siRNA for T-bet, STAT4, or STAT5 or a scrambled siRNA was transfected in a 24-well tissue culture plate for 24 hours. After wash, cells were cultured in OKT3-coated plates in the presence or absence of $50 \mathrm{ng} / \mathrm{ml} \mathrm{IL-12}$ for 3 days and TIM-3 expression was measured by flow cytometry.

Statistics. Statistical analysis was performed using Student's $t$ test. $P<0.05$ was considered significant. A scatter plot of the residuals was performed to determine the best cut point for analysis of the degree of IL-12 levels or TIM-3 frequency. This test was used to determine the levels of serum IL-12 or percentage of $\mathrm{TIM}-3^{+}$subsets (CD3, CD4, and CD8 cells) that separated the study cohort into 2 groups with the most statistically different progression-free survival. Progression-free survival was measured from the date of study entry until relapse or death from any cause. Patients alive and still at risk of relapse at last follow-up evaluation were censored for analysis of progression-free survival. Progression-free survival of all patients was estimated using the Kaplan-Meier method. The univariate associations between individual clinical features and survival were determined with the log-rank test.

Study approval. The use of human tissue samples for this study was approved by the Institutional Review Board of the Mayo Clinic/Mayo Foundation. Patients provided written, informed consent.

\section{Acknowledgments}

This work was supported in part by grants CA92104 and CA97274 from the NIH.

Received for publication July 5, 2011, and accepted in revised form February 1, 2012.

Address correspondence to: Zhi-Zhang Yang or Stephen M. Ansell, Division of Hematology and Internal Medicine, Mayo Clinic, 200 First St. SW, Rochester, Minnesota 55905, USA. Phone: 507.284.3805; Fax: 507.266.9277; E-mail:yang.zhizhang@mayo.edu (Z. Yang), ansell.stephen@mayo.edu (S.M. Ansell).
1. Dave SS, et al. Prediction of survival in follicular lymphoma based on molecular features of tumorinfiltrating immune cells. $N$ Engl J Med. 2004; 351(21):2159-2169.

2. Glas AM, et al. Gene-expression and immunohistochemical study of specific T-cell subsets and accessory cell types in the transformation and prognosis of follicular lymphoma. J Clin Oncol. 2007; 25(4):390-398.

3. Yang ZZ, Novak AJ, Stenson MJ, Witzig TE, Ansell $\mathrm{SM}$. Intratumoral CD $4+\mathrm{CD} 25+$ regulatory $\mathrm{T}$ cell-mediated suppression of infiltrating CD4+ $\mathrm{T}$ cells in B-cell non-Hodgkin lymphoma. Blood. 2006;107(9):3639-3646.

4. Yang ZZ, Novak AJ, Ziesmer SC, Witzig TE, Ansell SM. Attenuation of CD8(+) T-cell function by $\mathrm{CD} 4(+) \mathrm{CD} 25(+)$ regulatory $\mathrm{T}$ cells in $\mathrm{B}-$ cell non-Hodgkin's lymphoma. Cancer Res. 2006; 66(20):10145-10152.

5. Hilchey SP, De A, Rimsza LM, Bankert RB, Bernstein SH. Follicular lymphoma intratumoral CD $4+C D 25+$ GITR + regulatory $\mathrm{T}$ cells potently suppress CD3/CD28-costimulated autologous and allogeneic CD8+CD25- and CD4+CD25-T cells. Jimmunol. 2007;178(7):4051-4061.

6. Labidi SI, et al. Serum cytokines in follicular lymphoma. Correlation of TGF-beta and VEGF with survival. Ann Hematol. 2010;89(1):25-33.

7. Jones EA, Pringle JH, Angel CA, Rees RC. Th1/ Th2 cytokine expression and its relationship with tumor growth in B cell non-Hodgkin's lymphoma (NHL). Leuk Lymphoma. 2002;43(6):1313-1321.

8. Carreras J, et al. High numbers of tumor-infiltrating FOXP3-positive regulatory $\mathrm{T}$ cells are associated with improved overall survival in follicular lymphoma. Blood. 2006;108(9):2957-2964.

9. Gallimore A, et al. Induction and exhaustion of lymphocytic choriomeningitis virus-specific cytotoxic T lymphocytes visualized using soluble tetrameric major histocompatibility complex class I-peptide complexes. J Exp Med. 1998;187(9):1383-1393.

10. Zajac AJ, et al. Viral immune evasion due to persistence of activated $\mathrm{T}$ cells without effector function. J Exp Med. 1998;188(12):2205-2213.

11. Day CL, et al. PD-1 expression on HIV-specific T cells is associated with T-cell exhaustion and disease progression. Nature. 2006;443(7109):350-354.

12. D'Souza M, et al. Programmed death 1 expression on HIV-specific CD4+ T cells is driven by viral replication and associated with $\mathrm{T}$ cell dysfunction. JImmunol. 2007;179(3):1979-1987.

13. Ulsenheimer A, et al. Detection of functionally altered hepatitis $\mathrm{C}$ virus-specific CD4 T cells in acute and chronic hepatitis C. Hepatology. 2003; 37(5):1189-1198.

14. Urbani $S$, et al. PD-1 expression in acute hepatitis $C$ virus (HCV) infection is associated with HCV-specific CD8 exhaustion. JVirol. 2006;80(22):11398-11403.

15. Kasprowicz V, et al. High level of PD-1 expression on hepatitis $\mathrm{C}$ virus (HCV)-specific CD8+ and CD4+ T cells during acute $\mathrm{HCV}$ infection, irrespective of clinical outcome. J Virol. 2008;82(6):3154-3160.

16. Mumprecht S, Schurch C, Schwaller J, Solenthaler $\mathrm{M}$, Ochsenbein AF. Programmed death 1 signaling on chronic myeloid leukemia-specific T cells results in T-cell exhaustion and disease progression. Blood. 2009;114(8):1528-1536.

17. Ahmadzadeh $M$, et al. Tumor antigen-specific CD8 $T$ cells infiltrating the tumor express high levels of PD-1 and are functionally impaired. Blood. 2009;114(8):1537-1544.

18. Klein L, et al. Visualizing the course of antigen-specific CD8 and CD4 T cell responses to a growing tumor. Eur J Immunol. 2003;33(3):806-814.

19. Del Vecchio $M$, et al. Interleukin-12: biological properties and clinical application. Clin Cancer Res. 2007;13(16):4677-4685.

20. Ansell SM, et al. Randomized phase II study of interleukin-12 in combination with rituximab in previously treated non-Hodgkin's lymphoma patients. Clin Cancer Res. 2006;12(20 pt 1):6056-6063.

21. Sanchez-Fueyo A, et al. Tim-3 inhibits T helper type 1-mediated auto- and alloimmune responses and promotes immunological tolerance. Nat Immunol. 2003;4(11):1093-1101.

22. Sabatos CA, et al. Interaction of Tim-3 and Tim3 ligand regulates $\mathrm{T}$ helper type 1 responses and induction of peripheral tolerance. Nat Immunol. 2003;4(11):1102-1110.

23. Jones RB, et al. Tim-3 expression defines a novel population of dysfunctional $\mathrm{T}$ cells with highly elevated frequencies in progressive HIV-1 infection. J Exp Med. 2008;205(12):2763-2779.

24. Jin HT, et al. Cooperation of Tim-3 and PD- 1 in CD8 T-cell exhaustion during chronic viral infection. Proc Natl Acad Sci U S A. 2010;107(33):14733-14738.
25. Fourcade J, et al. Upregulation of Tim-3 and PD-1 expression is associated with tumor antigen-specific CD8+ T cell dysfunction in melanoma patients. J Exp Med. 2010;207(10):2175-2186.

26. Sakuishi K, Apetoh L, Sullivan JM, Blazar BR, Kuchroo VK, Anderson AC. Targeting Tim-3 and PD-1 pathways to reverse $\mathrm{T}$ cell exhaustion and restore anti-tumor immunity. J Exp Med. 2010; 207(10):2187-2194.

27. Zhou Q, et al. Co-expression of Tim-3 and PD-1 identifies a CD8+ T-cell exhaustion phenotype in mice with disseminated acute myelogenous leukemia. Blood. 2011;117(17):4501-4510.

28. Golden-Mason L, et al. Negative immune regulator Tim-3 is overexpressed on T cells in hepatitis $C$ virus infection and its blockade rescues dysfunctional CD4+ and CD8+ T cells. J Virol. 2009; 83(18):9122-9130.

29. Dorfman DM, et al. In vivo expression of B7-1 and B7-2 by follicular lymphoma cells can prevent induction of T-cell anergy but is insufficient to induce significant T-cell proliferation. Blood. 1997;90(11):4297-4306.

30. Gitelson E, et al. T-cell analysis in identical twins reveals an impaired anti-follicular lymphoma immune response in the patient but not in the healthy twin. Br J Haematol. 2002;116(1):122-127.

31. Hilchey SP, et al. Human follicular lymphoma CD39+-infiltrating T cells contribute to adenosinemediated $\mathrm{T}$ cell hyporesponsiveness. J Immunol. 2009;183(10):6157-6166

32. Toubai $\mathrm{T}$, et al. Effect of granulocyte colonystimulating factor on IL-12 p40 production during chemotherapy for B-cell lineage nonHodgkin's lymphoma patients. Eur J Haematol. 2006;77(5):403-409.

33. Trinchieri G. Interleukin-12 and the regulation of innate resistance and adaptive immunity. Nat Rev Immunol. 2003;3(2):133-146.

34. Anderson AC, et al. Promotion of tissue inflammation by the immune receptor Tim-3 expressed on innate immune cells. Science. 2007; 318(5853):1141-1143.

35. Akbar AN, Henson SM. Are senescence and exhaustion intertwined or unrelated processes that compromise immunity? Nat Rev Immunol. 2011;11(4):289-295.

36. Zhu J, Paul WE. Heterogeneity and plasticity of T 
helper cells. Cell Res. 2010;20(1):4-12.

37. Breitfeld D, et al. Follicular B helper T cells express CXC chemokine receptor 5, localize to B cell follicles, and support immunoglobulin production. J Exp Med. 2000;192(11):1545-1552.

38. Schaerli P, Willimann K, Lang AB, Lipp M, Loetscher P, Moser B. CXC chemokine receptor 5 expression defines follicular homing $\mathrm{T}$ cells with B cell helper function. J Exp Med. 2000; 192(11):1553-1562.

39. Johnston RJ, et al. Bcl6 and Blimp-1 are reciprocal and antagonistic regulators of $\mathrm{T}$ follicular helper cell differentiation. Science. 2009;325(5943):1006-1010.

40. Watford WT, Hissong BD, Bream JH, Kanno Y, Muul L, O'Shea JJ. Signaling by IL-12 and IL-23 and the immunoregulatory roles of STAT4. Immunol Rev. 2004;202:139-156
41. Klibi J, et al. Blood diffusion and Th1-suppressive effects of galectin-9-containing exosomes released by Epstein-Barr virus-infected nasopharyngeal carcinoma cells. Blood. 2009;113(9):1957-1966.

42. Brunda MJ, et al. Antitumor and antimetastatic activity of interleukin 12 against murine tumors. J Exp Med. 1993;178(4):1223-1230.

43. Colombo MP, Trinchieri G. Interleukin-12 in antitumor immunity and immunotherapy. Cytokine Growth Factor Rev. 2002;13(2):155-168.

44. Huang $X$, et al. Lymphoma endothelium preferentially expresses Tim- 3 and facilitates the progression of lymphoma by mediating immune evasion. J Exp Med. 2010;207(3):505-520.

45. Weng NP, Akbar AN, Goronzy J. CD28(-) T cells: their role in the age-associated decline of immune function. Trends Immunol. 2009;30(7):306-312.
46. Andrews NP, Fujii H, Goronzy JJ, Weyand CM. Telomeres and immunological diseases of aging. Gerontology. 2010;56(4):390-403.

47. Anderson AC, et al. T-bet, a Th1 transcription factor regulates the expression of Tim-3. Eur J Immunol. 2010;40(3):859-866.

48. Schulz EG, Mariani L, Radbruch A, Hofer T. Sequential polarization and imprinting of type 1 $\mathrm{T}$ helper lymphocytes by interferon-gamma and interleukin-12. Immunity. 2009;30(5):673-683.

49. Zhao J, et al. Human pregnancy up-regulates Tim3 in innate immune cells for systemic immunity. JImmunol. 2009;182(10):6618-6624.

50. Koguchi K, Anderson DE, Yang L, O'Connor KC, Kuchroo VK, Hafler DA. Dysregulated T cell expression of TIM3 in multiple sclerosis. J Exp Med. 2006;203(6):1413-1418. 